\title{
Quantum yield and morphology control of BODIPY-based supramolecular self-assembly with a chiral polymer inhibitor
}

\begin{abstract}
Atsushi Nagai, Kenta Kokado, Junpei Miyake and Yoshiki Chujo
Chiral rod-coil-type organoboron polymers S-poly and R-poly were prepared from the palladium-catalyzed SonogashiraHagihara coupling reaction of boron dipyrromethene-based monomer 1 , which has bisiodophenyl and decyl groups with $S$ - or $R-6,6^{\prime}$-diethynyl-2, $2^{\prime}$-dioctyloxy-1, $1^{\prime}$-binaphthyls (S-2 and R-2), in a solvent mixture (tetrahydrofuran (THF)/triethylamine $=2 / 1$ $(\mathrm{v} / \mathrm{v}))$ at $40^{\circ} \mathrm{C}$ for $24 \mathrm{~h}$. The obtained polymers were characterized by hydrogen-1 nuclear magnetic resonance (NMR), carbon-13 NMR ( ${ }^{13} \mathrm{C}$ NMR), boron-11 NMR ( ${ }^{11}$ B NMR) and infrared spectroscopy. The scanning electron microscopy (SEM) analysis of each chiral polymer clearly revealed micrometer-sized fiber-like structures formed by the aggregation of each particle, as we expected. Next, we examined the relationship between the ratio of photoluminescence $(\mathrm{PL})$ intensity $\left(/ / I_{0}=\mathrm{R}\right.$-poly/S-poly) and particle diameter, measured by dynamic light scattering analysis, versus the R-poly content of the mixed polymer of S-poly and R-poly in THF, which varied from 0 to $100 \%$. As a result, the PL intensity and diameter showed maximum and minimum (about $32 \mathrm{~nm}$ ) values, respectively, at $70 \%$ content, depending on the differences between both the molecular weights and absolute values of the chiral characters. These findings indicate that the PL intensity of S-poly influences morphology change by adding R-poly; that is, R-poly acts as an inhibitor toward the aggregation of S-poly. Furthermore, the SEM image of the mixed polymer (S-poly/R-poly $=30 / 70$ ) showed complete particle structures from nano- to micrometer sizes, which were roughly $480 \mathrm{~nm}$ to
\end{abstract} $1.19 \mu \mathrm{m}$ in diameter, and the $\Phi_{\mathrm{F}}$ of the mixed polymer was significantly high $(0.98)$.

Polymer Journal (2010) 42, 37-42; doi:10.1038/pj.2009.302

Keywords: boron dipyrromethene; chiral polymer; conjugated polymers; fluorescence; supramolecular

\section{INTRODUCTION}

Self-assembly provides a unique method for creating supramolecular functional materials. ${ }^{1,2}$ In particular, the controlled morphology of chromophores at the supramolecular level on the nano- to micrometer scale is important because of the potential applications of these molecules in optoelectronic devices. ${ }^{3-5}$ Recently, self-assemblies of oligo ( $p$-phenylene-ethynylene) derivatives as rigid $\pi$-conjugated molecules have attracted a great deal of attention. ${ }^{6-10}$ Controlled ordering of the self-assembled architectures requires skillful design of molecular constituents. Successful examples are spherical to tubular or cylindrical assemblies formed by attaching chiral handles ${ }^{11,5,12-16}$ or by the sergeant-and-soldiers ${ }^{17-20}$ coassembly approach. More recently, a rare transition from vesicles to helical tubules has been obtained by sergeant-and-soldiers coassembly of chiral and achiral oligo( $p$-phenylene-ethynylene) derivatives. ${ }^{21,22}$ However, transitions of $\pi$-conjugated molecules or polymers from tubules or fibers to vesicles, that is, inhibitions of tubule or fiber formations, have not yet been investigated. In contrast to synthetic chemistry, inhibitions of their formations are studied in biochemistry. For example, islet amyloid fibril formation (IAPP) stabilized by hydrogen bonds, which is involved in devastating diseases such as type II diabetes mellitus, can be prevented by altering the amino-acid sequence ${ }^{23}$ and analogs of IAPP methylated at amide bonds, ${ }^{24,25}$ as well as by using small molecules ${ }^{26,27}$ as inhibitors, which act by replacing interactions such as hydrogen bonds and $\pi-\pi$ stacking during a part of amyloid fibril formation. Inspired by these interesting phenomena, we wanted to explore whether a chiral-conjugated polymer acts as an inhibitor of tubules or fibers assembled by the $\pi$-stacking interaction of an opposite chiralconjugated polymer. If possible, this would simultaneously share the controls of morphology and emission by repressing self-assembly during each $\pi$-stacking interaction. Previously, we demonstrated the synthesis of highly fluorescent organoboron polymers with supramolecular self-assembled fiber or network structures by incorporating boron dipyrromethene (BODIPY) dye into a poly(p-phenylene-ethynylene) derivative ${ }^{28}$ or poly(methyl methacrylate). ${ }^{29}$ The intriguing formation of their supramolecular self-assembly leads to a low quantum yield. In this study, we reveal the control of quantum yields and the unprecedented transition from fiber to particle in the 
self-assembly of a chiral BODIPY-based poly( $p$-phenylene-ethynylene) derivative using the chiral polymer as an inhibitor.

\section{EXPERIMENTAL PROCEDURE}

\section{Instrumentation}

The hydrogen-1 $\left({ }^{1} \mathrm{H}\right)(400 \mathrm{MHz})$, carbon-13 $\left({ }^{13} \mathrm{C}\right)(100 \mathrm{MHz})$ and boron-11 $\left({ }^{11} \mathrm{~B}\right)(128 \mathrm{MHz})$ nuclear magnetic resonance (NMR) spectra were recorded on JNM-EX400 spectrometers (JEOL, Tokyo, Japan). ${ }^{1} \mathrm{H}$ NMR and ${ }^{13} \mathrm{C}$ NMR spectra used tetramethylsilane as an internal standard in $\mathrm{CDCl}_{3}$, and ${ }^{11} \mathrm{~B}$ NMR spectra were referenced externally to $\mathrm{BF}_{3} \cdot \mathrm{OEt}_{2}$ (sealed capillary). The number-average molecular weight $\left(M_{\mathrm{n}}\right)$ and molecular weight distribution (weight-average molecular weight/number-average molecular weight $\left.\left(M_{\mathrm{w}} / M_{\mathrm{n}}\right)\right)$ values of all polymers were estimated by size-exclusion chromatography with a G3000HXI system (TOSOH Corporation, Tokyo, Japan) equipped with three consecutive polystyrene gel columns (TOSOH gels: $\alpha-4000, \alpha-3000$ and $\alpha-2500$ ) and a refractive index and ultraviolet detector at $40{ }^{\circ} \mathrm{C}$. The system was operated at a flow rate of $1.0 \mathrm{ml} \mathrm{min}^{-1}$ with tetrahydrofuran as the eluent. Polystyrene standards were used for calibration. Ultraviolet (UV)-visible spectra were recorded on a UV-3600 spectrophotometer (SHIMADZU Corporation, Kyoto, Japan), and fluorescence emission spectra were measured on a Fluoromax-4 spectrofluorometer (HORIBA Limited, Tokyo, Japan). Scanning electron microscopy (SEM) images were obtained using JSM-5600 (JEOL) operated at an accelerating voltage of $15 \mathrm{kV}$. SEM samples were prepared by placing desired precipitates on the conducting tape attached to the SEM grid.

\section{Materials}

Boron dipyrromethene-based bisiodophenyl monomer $\mathbf{1}^{28,30,31}$ and $S-6,6^{\prime}$ diethynyl-2,2'-dioctyloxy-1,1'-binaphthyl $(\mathbf{S}-2)^{32}$ were prepared according to the literature. Tetrahydrofuran (THF) and triethylamine were purified using a two-column solid-state purification system (Glasscotour System; Joerg Meyer, Irvine, CA, USA). Other reagents were commercially available and used as received.

\section{Synthesis of R-2}

$R$-6, '6'-diethynyl-2,2'-dioctyloxy-1.1'-binaphthyl (R-2) was prepared in a similar manner to S-2 using $R$-binaphthol as starting material. Yield $=68 \%,{ }^{1} \mathrm{H}$ NMR $\left(\mathrm{CDCl}_{3}\right) \delta=8.03(\mathrm{~s}, 2 \mathrm{H}), 7.88(\mathrm{~d}, 2 \mathrm{H}, J=9.0 \mathrm{~Hz}), 7.40(\mathrm{~d}, 2 \mathrm{H}, J=9.0 \mathrm{~Hz}), 7.24$ (d, $1 \mathrm{H}, J=7.1 \mathrm{~Hz}), 7.06(\mathrm{~d}, 2 \mathrm{H}, \mathrm{J}=8.8 \mathrm{~Hz}), 3.98-3.89(\mathrm{~m}, 4 \mathrm{H}), 3.07(\mathrm{~s}, 2 \mathrm{H})$, $1.40-1.38(\mathrm{~m}, 4 \mathrm{H}), 1.23-1.21(\mathrm{~m}, 4 \mathrm{H}), 1.09-1.00(\mathrm{~m}, 16 \mathrm{H}), 0.86(6 \mathrm{H}, \mathrm{t}$, $J=7.3 \mathrm{~Hz}$ ) p.p.m. High resolution mass (Electron Ionization) calculated value for $\mathrm{C}_{40} \mathrm{H}_{46} \mathrm{O}_{2}: \mathrm{m} / z$ 558.3498; observed value: $\mathrm{m} / z$ 558.3499. Anal. calculated for $\mathrm{C}_{40} \mathrm{H}_{46} \mathrm{O}_{2}$ : C, 85.98; $\mathrm{H}, 8.30$; observed values: $\mathrm{C}, 86.07 ; \mathrm{H}, 8.46$.

\section{Synthesis of S-poly}

A typical procedure was followed: Triethylamine $(0.70 \mathrm{ml})$ was added to a solution of 1 ( $0.06 \mathrm{~g}, 0.07 \mathrm{mmol}), \mathbf{R}-2(0.04 \mathrm{~g}, 0.07 \mathrm{mmol}), \mathrm{Pd}\left(\mathrm{PPh}_{3}\right)_{4}(4.00 \mathrm{mg}$, $3.50 \mu \mathrm{mol})$ and $\mathrm{CuI}(0.70 \mathrm{mg}, 3.50 \mu \mathrm{mol})$ in THF $(1.40 \mathrm{ml})$ at room temperature under nitrogen. After stirring the mixture at $40^{\circ} \mathrm{C}$ for $24 \mathrm{~h}$, the solvent was evaporated in vacuo. The residue was extracted with $\mathrm{CHCl}_{3}$ and washed with $10 \%$ aqueous ammonia, then with water, and dried over $\mathrm{MgSO}_{4}$. Thereafter, volatile products were evaporated. The residue was dissolved in a small amount of $\mathrm{CHCl}_{3}$ and poured into a large excess of methanol to precipitate the polymer. The polymer was collected by filtration with suction. The polymer was again purified into hexane by repeated precipitation from a small amount of $\mathrm{CHCl}_{3}$ and dried under vacuum at $60^{\circ} \mathrm{C}$ for $12 \mathrm{~h}$. S-poly was obtained as an orange solid. Yield $=83 \% . M_{\mathrm{n}}=12100 .{ }^{1} \mathrm{H}$ NMR $\left(\mathrm{CDCl}_{3}\right)$ : $\delta=0.78-1.52(51 \mathrm{H}), 1.60-1.72(4 \mathrm{H}), 2.23-2.55(8 \mathrm{H}), 2.76-2.92(6 \mathrm{H}), 2.97-$ $3.12(4 \mathrm{H}), 3.81-4.22(4 \mathrm{H}), 7.00-7.12(2 \mathrm{H}), 7.21-7.45(10 \mathrm{H}), 7.80-7.94(2 \mathrm{H})$ 7.98-8.14 (2H) p.p.m. ${ }^{13} \mathrm{C}$ NMR $\left(\mathrm{CDCl}_{3}\right) \delta=9.3,13.4,13.9,14.2,14.4,15.1$, $17.5,22.5,25.6,28.6,29.0,29.1,29.2,29.3,29.4,29.5,29.6,30.6,31.7,31.8$, $31.9,69.5,89.2,91.1,92.5,116.0,117.8,120.1,121.8,125.1,128.7,129.2,129.3$, 131.2, 131.3, 132.4, 133.5, 133.7, 144.9, 153.0, 156.3 p.p.m. ${ }^{11} \mathrm{~B}$ NMR $\left(\mathrm{CDCl}_{3}\right): \delta=-13.8$ p.p.m. $\mathrm{IR}(\mathrm{KBr}): v=2924,2855,2202,1588,1546,1480$, $1263,977,797 \mathrm{~cm}^{-1}$

\section{Synthesis of R-poly}

R-poly was prepared from $\mathbf{1}$ with S-2 in $76 \%$ yield as an orange solid. $M_{\mathrm{n}}=9200 .{ }^{1} \mathrm{H}$ NMR $\left(\mathrm{CDCl}_{3}\right): \delta=0.73-1.49(51 \mathrm{H}), 1.59-1.73(4 \mathrm{H}), 2.25-2.51$ $(8 \mathrm{H}), 2.77-2.95(6 \mathrm{H}), 2.99-3.14(4 \mathrm{H}), 3.83-4.18(4 \mathrm{H}), 7.04-7.19(2 \mathrm{H}), 7.22-$ $7.48(10 \mathrm{H}), 7.82-7.91(2 \mathrm{H}) 8.00-8.12(2 \mathrm{H})$ p.p.m. ${ }^{13} \mathrm{C}$ NMR $\left(\mathrm{CDCl}_{3}\right) \delta=9.4$, 13.6, 13.9, 14.0, 14.1, 15.0, 17.5, 22.6, 25.6, 28.7, 29.0, 29.1, 29.3, 29.3, 29.4, 29.5, 29.6, 30.4, 31.7, 31.8, 31.9, 69.5, 89.2, 91.2, 92.3, 115.9, 117.9, 120.1, 121.9, $125.2,128.7,129.2,129.3,131.4,131.5,132.6,133.6,133.8,144.9,152.0,155.3$ p.p.m. ${ }^{11} \mathrm{~B}$ NMR $\left(\mathrm{CDCl}_{3}\right): \delta=-13.9$ p.p.m. $\mathrm{IR}(\mathrm{KBr}): v=2923,2856,2204,1587$, $1546,1481,1262,975,796 \mathrm{~cm}^{-1}$. a

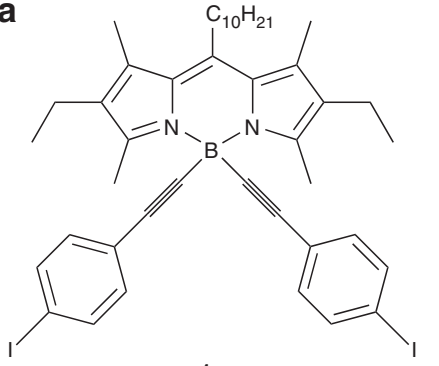
1

b

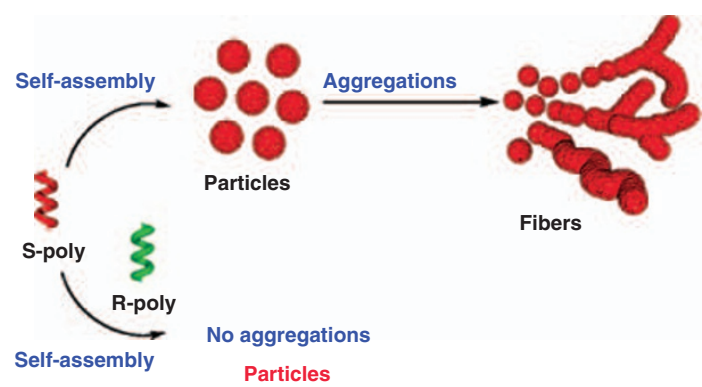

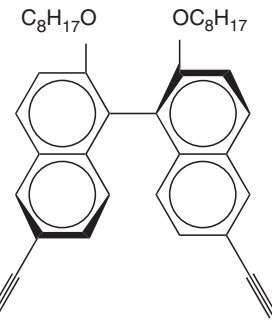

S-2 or R-2

Particles

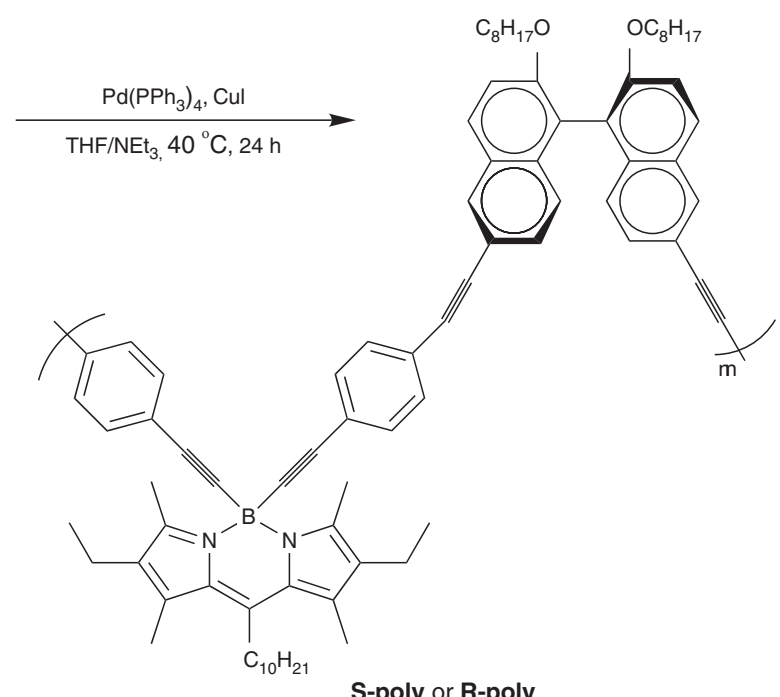

S-poly or R-poly

Scheme 1 (a) Polymerization of boron dipyrromethene (BODIPY)-based bisiodophenyl monomer 1 with $S$-6,6'-diethynyl-2,2'-dioctyloxy-1,1'-binaphthyl (S-2) or $R$-6, $6^{\prime}$-diethynyl-2,2'-dioctyloxy-1,1'-binaphthyl (R-2), and (b) transition from particles to fibers and particle formation by using chiral polymer as an inhibitor. 


\section{RESULTS AND DISCUSSION}

Synthesis and characterization of chiral polymers

(S-poly and R-poly)

The two chiral polymers S-poly and R-poly were synthesized by a palladium-catalyzed Sonogashira-Hagihara cross-coupling reaction of BODIPY-based bisiodophenyl monomer, ${ }^{28,29}$ which was prepared in a manner similar to that described by Ziessel and colleagues, ${ }^{30,31}$ with S-2 and R-2 in the presence of CuI $(5.0 \mathrm{~mol} \%)$ in a solvent mixture $(\mathrm{THF} /$ triethylamine $=2 / 1(\mathrm{v} / \mathrm{v}))$ at $40{ }^{\circ} \mathrm{C}$ for $24 \mathrm{~h}$ (Scheme 1a). This process afforded orange solids in yields of over $70 \%$ after precipitation into methanol. The polymers readily dissolve in common organic solvents, such as THF, $\mathrm{CH}_{2} \mathrm{Cl}_{2}, \mathrm{CHCl}_{3}$ and toluene. The expected structures of the obtained polymers were confirmed by ${ }^{1} \mathrm{H},{ }^{13} \mathrm{C}$ and ${ }^{11} \mathrm{~B}$ NMR, and by infrared spectroscopy. For example, in the ${ }^{1} \mathrm{H}$ NMR spectra of both polymers, the characteristic peaks assignable to four methyl protons and one ethylene proton at the meso position in the BODIPY unit were observed at around 2.25 and 2.77 p.p.m. and at 3.10 p.p.m., respectively, and the peaks at around 3.83-4.18 p.p.m. were assigned to ethylene protons neighboring oxygen atoms of dioctoxyl groups in the binaphthyl unit. The infrared spectra showed an absorption peak at around $2200 \mathrm{~cm}^{-1}$, assignable to stretching of the carbon-carbon triple bond in the backbone. These results confirmed an efficient coupling reaction between $\mathbf{1}$ and S-2 or R-2. Furthermore, the tetracoordination states of boron atoms in the obtained polymers were confirmed by ${ }^{11} \mathrm{~B}$ NMR spectroscopy (S-poly: $\delta_{\mathrm{B}}=-13.8$ p.p.m., R-poly: $\delta_{\mathrm{B}}=-13.9$ p.p.m.), indicating that the polymerization proceeded without any damage to the tetrahedral structure in the BODIPY moiety. The $M_{\mathrm{n}}$, measured by sizeexclusion chromatography in THF, of S-poly and R-poly were 12100 and 9200, respectively, and the molecular weight distributions $\left(M_{\mathrm{W}} /\right.$ $M_{\mathrm{n}}$ ) of the polymers were very wide (S-poly: $M_{\mathrm{w}} / M_{\mathrm{n}}=9.18$ and Rpoly: $M_{\mathrm{W}} / M_{\mathrm{n}}=8.21$ ), predicting that these wide distributions will lead to the formation of supramolecular self-assembled structures, such as particles and fibers, ${ }^{28}$ supported by the dynamic light scattering measurement of S-poly and R-poly (discussion later).

\section{Optical properties}

The specific rotations $\left([\alpha]_{\mathrm{D}}^{25}\right)$ of the obtained polymers had contrasting values (S-poly: $[\alpha]_{\mathrm{D}}^{25}=206.9^{\circ}$ and R-poly: $[\alpha]_{\mathrm{D}}^{25}=-163.8^{\circ}$ ) in THF $(c=0.012 \mathrm{~g}$ per $100 \mathrm{ml})$, and the circular dichroism spectra of each polymer also showed mirror Cotton effects at 200-250 and 260-430 nm, attributable to aromatic and p-phenylene-ethynylene units, respectively. However, no Cotton effects at around $518 \mathrm{~nm}$, corresponding to the BODIPY moiety, were observed due to soft B-N chelating bond in the BODIPY moiety (Figure 1). These data certainly indicate that S-poly and R-poly have contrasting higher-order structures, such as right- and left-handed helical conformations.

Photophysical characterization of the obtained polymers and of a mixture of S-poly and R-poly (50/50) was conducted. Figure 2 shows the UV-visible absorption and photoluminescence (PL) observed in THF $\left(1.0 \times 10^{-5} \mathrm{moll}^{-1}\right)$. Measured absorptions of all compounds, corresponding to $\pi-\pi^{*}$ transition were observed at around 240,334 and $518 \mathrm{~nm}$, assignable to aromatic, p-phenylene-ethynylene and BODIPY ligand, ${ }^{28,30,31}$ respectively (Figure 1a). The molar absorption coefficient at $334 \mathrm{~nm}$ of S-poly $\left(\varepsilon=1.18 \times 10^{4} \mathrm{M}^{-1} \mathrm{~cm}^{-1}\right)$ was higher than that of R-poly $\left(\varepsilon=1.00 \times 10^{4} \mathrm{M}^{-1} \mathrm{~cm}^{-1}\right)$, depending on the difference in their molecular weights. However, their coefficients at $518 \mathrm{~nm}$ had almost the same values (S-poly: $\varepsilon=1.03 \times 10^{4} \mathrm{M}^{-1} \mathrm{~cm}^{-1}$ and R-poly: $\left.\varepsilon=1.04 \times 10^{4} \mathrm{M}^{-1} \mathrm{~cm}^{-1}\right)$. Interestingly, higher molar absorption coefficients were observed with the mixed polymer than with S-poly and R-poly, especially for the BODIPY ligand

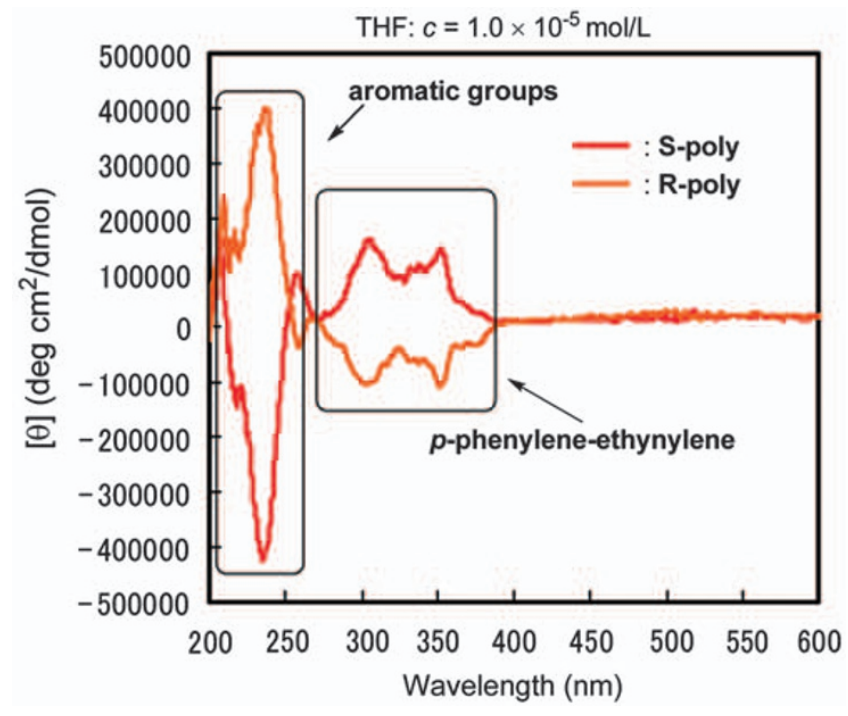

Figure 1 Circular dichroism spectra of S-poly and R-poly in tetrahydrofuran (THF) $\left(1.0 \times 10^{-5} \mathrm{~mol} \mathrm{I}^{-1}\right)$.
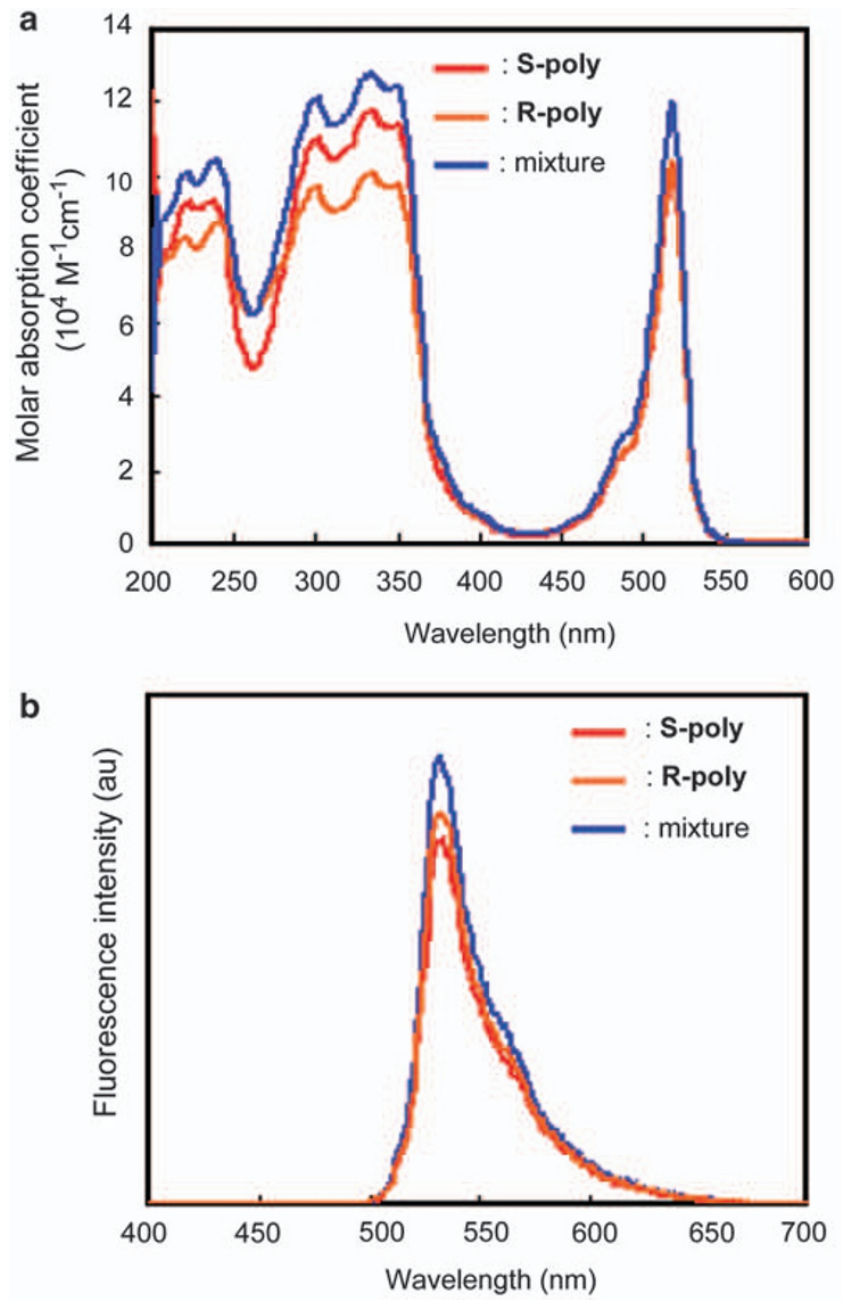

Figure 2 (a) Ultraviolet (UV)-visible absorption spectra of S-poly, R-poly and mixture (S-poly/R-poly $=50 / 50)$ in tetrahydrofuran (THF) $\left(1.0 \times 10^{-5} \mathrm{~mol} \mathrm{I}^{-1}\right)$, and (b) emission spectra of S-poly, R-poly and mixture (S-poly/R-poly= $50 / 50)$ in THF $\left(1.0 \times 10^{-5} \mathrm{moll}^{-1}\right)$. 
$\left(\varepsilon=1.21 \times 10^{4} \mathrm{M}^{-1} \mathrm{~cm}^{-1}\right)$ at $518 \mathrm{~nm}$. Similarly, in PL spectra in THF, the emission maximum of the mixed polymer at $532 \mathrm{~nm}$, which was excited at $334 \mathrm{~nm}$, was higher than those of S-poly and R-poly. Furthermore, the absolute fluorescence quantum yield $\left(\Phi_{\mathrm{F}}\right)$ of the mixed polymer (excited at $334 \mathrm{~nm}$ in THF), measured by the integrating sphere method, was the highest; S-poly: $\Phi_{\mathrm{F}}=0.81, \mathbf{R}$ poly: $\Phi_{\mathrm{F}}=0.86$ and the mixed polymer: $\Phi_{\mathrm{F}}=0.90$. These results indicate that the increase in both UV-visible and emission peaks of a simple mixture of the two polymers would cause some changes in morphology in THF solution. Therefore, we expect an inhibition of individual aggregation by mixing two chiral polymers.

To investigate the emission behavior from morphology change in THF, we carried out a dynamic light scattering study to complement the PL spectra results. Figure 3 presents the relationships of the ratio of $\mathrm{PL}$ intensity $\left(I / I_{0}=\mathbf{R}\right.$-poly $) / \mathbf{S}$-poly $)$ and of particle diameter with the

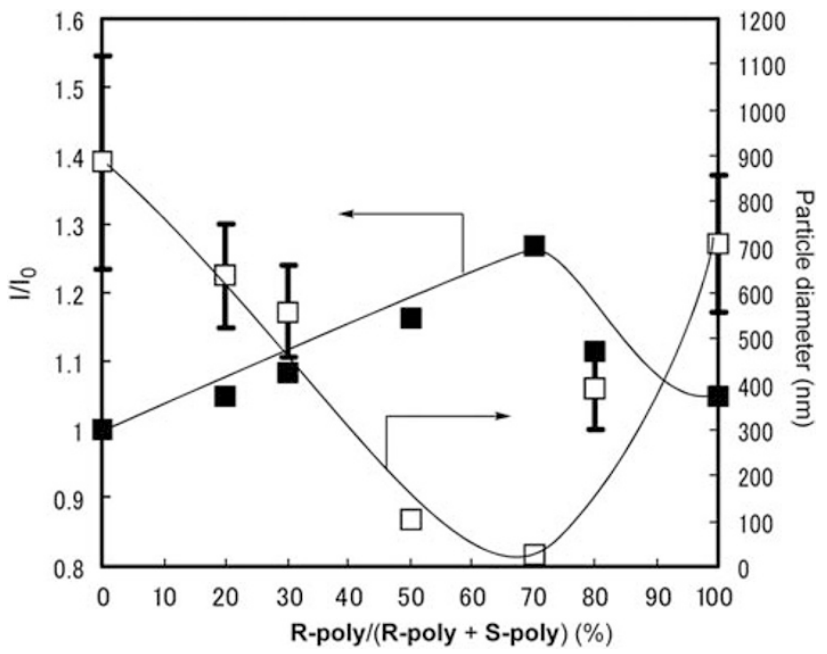

Figure 3 Relationship between R-poly/(R-poly+S-poly); emission intensity (I) of R-poly at $532 \mathrm{~nm} /$ emission intensity $\left(\mathrm{I}_{0}\right)$ of S-poly at $532 \mathrm{~nm}$, in tetrahydrofuran (THF) $\left(1.0 \times 10^{-5} \mathrm{~mol}^{-1}\right)$; and particle diameter measured by dynamic light scattering analysis in THF $\left(8.6 \times 10^{-3} \mathrm{~mol} \mathrm{I}^{-1}\right)$.
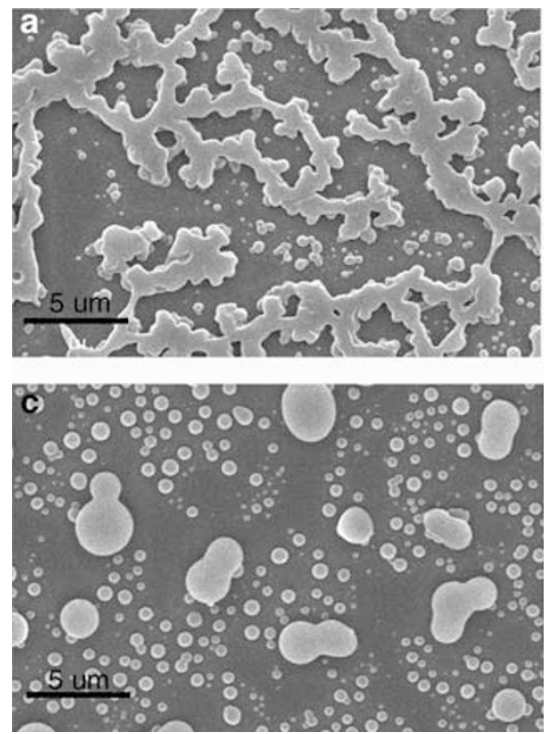

R-poly content of the mixed polymer of S-poly and R-poly in THF, which varied from 0 to $100 \%$. The PL intensity ratio gradually increased with increasing content of R-poly up to $70 \%$, and then a decrease in the ratio was observed between 70 and $100 \%$ content. Conversely, the diameters decreased with increasing content of R-poly up to $70 \%$, and increased with further content increase. As a result, as per our expectations, the PL intensity and diameter showed maximum and minimum (about $32 \mathrm{~nm}$ ) values, respectively, at $70 \%$ content, probably because of the differences in both the molecular weights and absolute values of chiral characters. These findings support the hypothesis that the PL intensity of S-poly influences morphology change by adding R-poly; that is, R-poly acts as an inhibitor of the aggregation of $\mathbf{S}$-poly, as previously suggested. Further evidence of inhibition of individual aggregation was provided by morphological studies using SEM. S-poly and R-poly formed micrometer-sized fiber-like structures ${ }^{28}$ by regularly aggregating selfassembled particles, as shown in Figures $4 \mathrm{a}$ and $\mathrm{b}$. By contrast, the SEM image of the mixed polymer $(\mathbf{S}-$ poly/R-poly=30/70) showed complete particle structures from nano- to micrometer sizes, which were roughly $480 \mathrm{~nm}$ to $1.19 \mu \mathrm{m}$ in diameter (Figure $4 \mathrm{~d}$ ). Furthermore, the SEM images of the mixed polymer (50/50) showed the contamination of particles and small amounts of aggregative formation (Figure 4c).

To assess their inhibition behavior, ${ }^{1} \mathrm{H}$ NMR experiments were carried out at $25^{\circ} \mathrm{C}$ in $\mathrm{CDCl}_{3}\left(1.0 \times 10^{-2} \mathrm{M}\right.$ ) (Figure 5). The ${ }^{1} \mathrm{H}$ NMR spectra of $\mathbf{S}$ - and R-poly showed mostly broad peaks. By contrast, the ${ }^{1} \mathrm{H}$ NMR spectra of mixed polymers at 50 and $70 \%$ R-poly contents showed sharper peaks, and the ethyl protons of long alkyl chains in the BODIPY units at 1.0-1.5 p.p.m. were shifted downfield (around 2.00 p.p.m.), supporting the hypothesis that the conformations of mixed polymers are different in solution states as compared with those of S- and R-poly. Furthermore, X-ray diffractions of S-poly and R-poly showed $d$-spacings of around $3.48 \AA$, which are characteristic of $\pi$-stacked packing, and a signal at the small-angle region corresponding to an interlayer spacing of $12.63 \AA$ (Figure 6). However, characteristic spacing assignable to $\pi$-stacked packing of mixed polymers at $70 \%$ R-poly content was not observed. These data indicate that the addition of R-poly prevents the generation of $\pi$-stacking
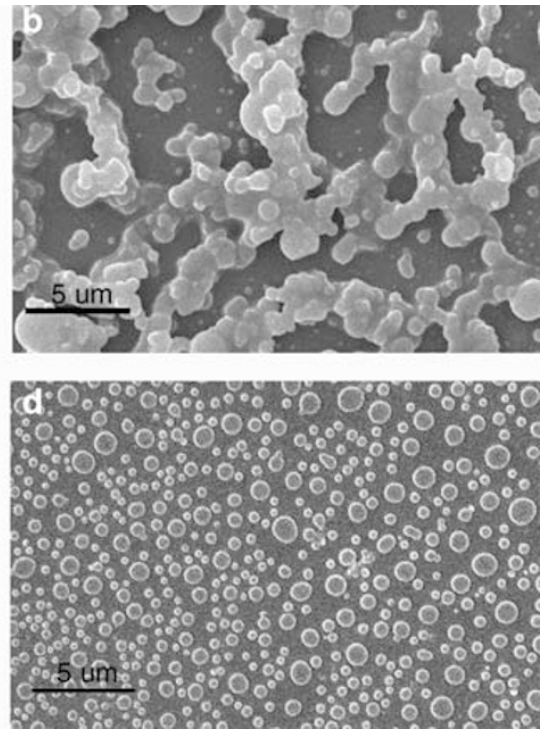

Figure 4 Scanning electron microscopy images of (a) S-poly, (b) R-poly, (c) mixture (R-poly/(R-poly+S-poly)=50) and (d) mixture (R-poly/(R-poly+ $\mathrm{S}$-poly) $=70$ ) (tetrahydrofuran, $8.6 \times 10^{-3} \mathrm{~mol} \mathrm{I}^{-1}$ ) dried at room temperature for $24 \mathrm{~h}$ on glass. 
a

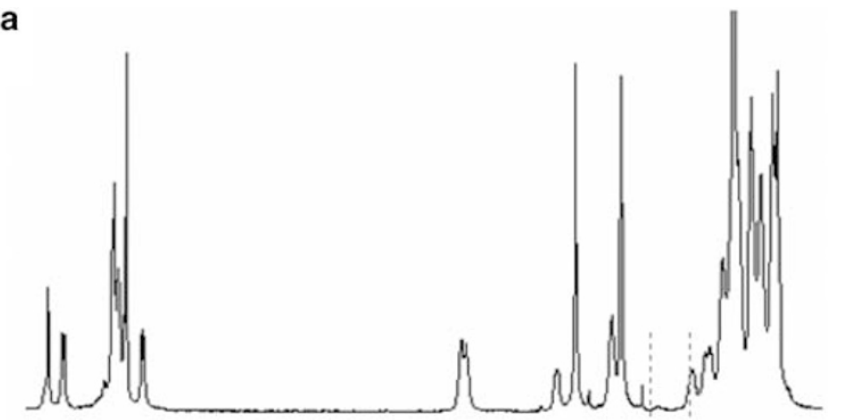

b

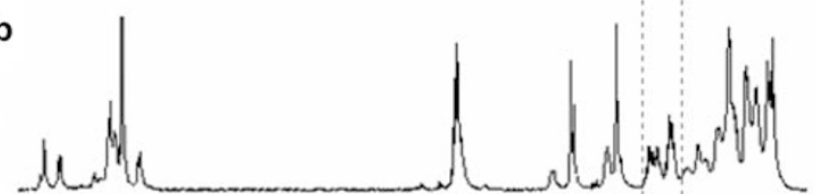

c
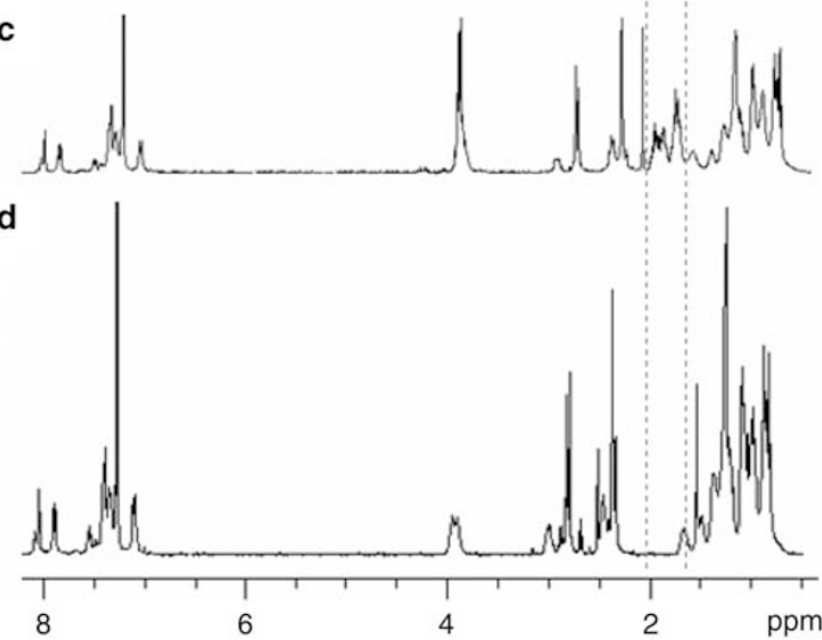

Figure 5 Hydrogen-1 nuclear magnetic resonance spectra $\left(\mathrm{CDCl}_{3}\right)$ of $(\mathbf{a})$ S-poly, (b) the mixed polymer (S-poly/R-poly=50/50), (c) the mixed polymer (S-poly/R-poly=30/70) and (d) R-poly.

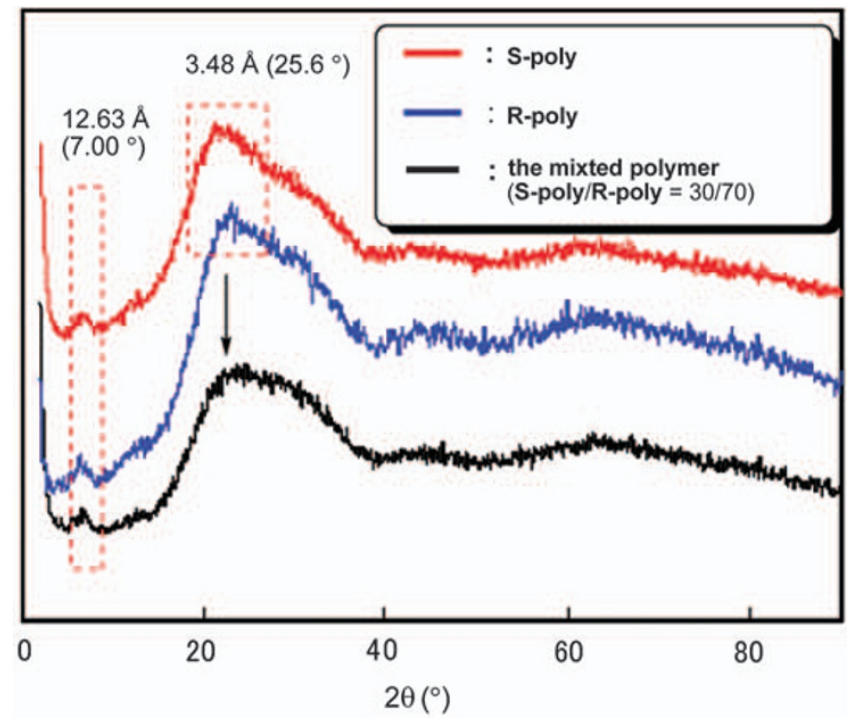

Figure 6 X-ray diffraction patterns of S-poly, R-poly and the mixed polymer (S-poly/R-poly=30/70). transition from particle to fiber structures in the self-assembly of S-poly; that is, R-poly effectively acts as a chiral polymer inhibitor (Scheme $1 \mathrm{~b}->$ ). Finally, the $\Phi_{\mathrm{F}}$ value of the mixed polymer at $70 \%$ content was significantly high (0.98).

\section{CONCLUSION}

Chiral rod-coil-type organoboron polymers S-poly and R-poly were prepared by a palladium-catalyzed Sonogashira-Hagihara coupling reaction of BODIPY-based monomer 1 having bisiodophenyl and decyl groups with S-2 and R-2. The SEM analysis of each chiral polymer revealed micrometer-sized fiber-like structures formed by the aggregation of each particle; however, the mixed polymer (S-poly/ $\mathbf{R}$-poly $=30 / 70$ ) showed complete particle structures from nano- to micrometer sizes, which were roughly $480 \mathrm{~nm}$ to $1.19 \mu \mathrm{m}$ in diameter, and the $\Phi_{\mathrm{F}}$ value of the mixed polymer increased up to 0.98 . More research is in progress to investigate the morphology change of this behavior using low-molecular-weight model compounds in detail.

1 Whiteside, G. M. \& Grzybowski, B. Self-assembly at all scales. Science 295, 2418-2421 (2002)

2 Brunsveld, L., Folmer, B. J. B, Meijer, E. W. \& Sijbesma, R. P. Supramolecular polymers. Chem. Rev. 101, 4071-4097 (2001).

3 Lehn, J.- M. Supramolecular Chemistry, Concepts and Perspectives, VCH, Weinheim, 1995.

4 Rowan, A. E. \& Nolte, R. J. M. Helical molecular programming. Angew. Chem. Int. Ed. 37, 63-68 (1998)

5 Cornelissen, J. J. L. M., Rowan, A. E., Nolte, R. J. M. \& Sommerdijk, N. A. J. M. Chiral architectures from macromolecular building blocks. Chem. Rev. 101, 4039-4070 (2001).

6 Samorí, P., Francke, V., Müllen, K. \& Rabe, J. P. Self-assembly of a conjugated polymer: from molecular rods to a nanoribbon architecture with molecular dimensions. Chem. Eur. J. 5, 2312-2317 (1999).

7 Samorí, P., Shiharulidze, I., Francke, V., Müllen, K. \& Rabe, J. P. Nanoribbons from conjugated macromolecules on amorphous substrates observed by SFM and TEM. Nanotechnology 10, 77-80 (1999).

8 Bunz, U. H. F. Poly(aryleneethynylene)s: syntheses, properties, structures, and applications. Chem. Rev. 100, 1605-1644 (2000).

9 Bunz, U. H. F. Poly(p-phenyleneethynylene)s by alkyne metathesis. Acc. Chem. Res. 34, 998-1010 (2001).

10 Zahn, S. \& Swager, T. M. Three-dimensional electronic delocalization in chiral conjugated polymers. Angew. Chem. Int. Ed. 114, 4225-4230 (2002).

$11 \mathrm{Kim}$, B.- S., Hong, D.- J., Bae, J. \& Lee, M. Controlled self-assembly of carbohydrate conjugate rod-coil amphiphiles for supramolecular multivalent ligands. J. Am. Chem. Soc. 127, 16333-16337 (2005).

12 Yashima, E., Maeda, K. \& Nishimura, T. Detection and amplification of chirality by helical polymers. Chem. Eur. J. 10, 42-51 (2004).

13 Jonkehejin, P., Miura, A., Zdanowska, M., Hoeben, F. J. M., De Feyter, S., Schenning, A. P. H. J., De Schryver, F. C. \& Meijer, E. W. $\pi$-Conjugated Oligo-(p-phenylenevinylene) rosettes and their tubular self-assembly. Angew. Chem. Int. Ed. 43, 74-78 (2004).

14 Ajayaghosh, A., Vijayakumar, C., Varghese, R. \& George, S. J. Cholesterol-aided supramolecular control over chromophore packing: twisted and coiled helices with distinct optical, chiroptical, and morphological features. Angew. Chem. Int. Ed. 45, 456-460 (2006).

15 Hill, J. P., Jin, W., Kosaka, A., Fukushima, T., Ichihara, H., Shimomura, T., Ito, K., Hashizume, T., Ishi, N. \& Aida, T. Self-assembled hexa-peri-hexabenzocoronene graphitic nanotube Science 304, 1481-1483 (2004).

16 Bae, J., Choi, J.- H., Yoo, Y.- S., Oh, N.- K., Kim, B.- S. \& Lee, M. Helical nanofibers from aqueous self-assembly of an Oligo(p-phenylene)-based molecular dumbbell. J. Am. Chem. Soc. 127, 9668-9669 (2005).

17 Geen, M. M., Park, J.- W., Sato, T., Teramoto, A., Lifson, S., Selinger, R. L. B. \& Selinger, , J. V. The macromolecular route to chiral amplification. Angew. Chem. Int. Ed. 38, 3138-3154 (1999).

18 Schenning, A. P. H. J., Kibinger, A. F. M., Biscarini, F., Cavallini, M., Cooper, H. J., Derrick, P. J., Feast, W. J., Lazzaroni, R., Leclère, P., McDonel, L. A., Meijer, E. W. $\&$ Meskers, S. C. J. Supramolecular organization of $\alpha, \alpha^{\prime}$-disubstituted sexithiophenes. J. Am. Chem. Soc. 124, 1269-1275 (2002).

19 Wilson, A. J., Masuda, M., Sijbesma, R. P. \& Meijer, E. W. Chiral amplification in the transcription of supramolecular helicity into a polymer backbone. Angew. Chem. Int. Ed. 44, 2275-2279 (2005).

20 Ajayaghosh, A., Varghese, R., George, S. J. \& Vijayakumar, C. Transcription and amplification of molecular chirality to oppositely biased supramolecular $\partial$ helices. Angew. Chem. Int. Ed. 45, 1141-1144 (2006).

21 Ryu, J.- H., Kim, H.- J., Huang, Z., Lee, E. \& Lee, M. Self-assembling molecular dumbbells: from nanohelices to nanocapsules triggered by guest intercalation. Angew. Chem. Int. Ed. 45, 5304-5307 (2006) 
22 Ajayaghosh, A., Varghese, R., Mahesh, S. \& Praveen, V. K. From vesicles to helical nanotubes: a sergeant-and-soldiers effect in the self-assembly of Oligo (p-phenyleneethynylene)s. Angew. Chem. Int. Ed. 45, 7729-7732 (2006).

23 Wastermark, P., Engström, U., Johnson, K. H., Westermark, G. T. \& Betsholtz, C. Islet amyloid polypeptide: pinpointing amino acid residues linked to amyloid fibril formation. Proc. Natl Acad. Sci., USA 87, 5036-5040 (1990).

24 Yan, L. M., Tatarek-Nossol, M., Velkova, A., Kazantzis, A. \& Kapurniotu, A. Design of a mimic of nonamyloidogenic and bioactive human islet amyloid polypeptide (IAPP) as nanomolar affinity inhibitor of IAPP cytotoxic fibrillogenesis. Proc Natl. Acad. Sci., USA 103, 2046-2051 (2006).

25 Yan, L. M., Velkova, A., Tatarek-Nossol, M., Andreetto, E. \& Kapurniotu, A. IAPP mimic blocks AâCytotoxic self-assembly: cross-suppression of amyloid toxicity of Aâ and IAPP suggests a molecular link between alzheimer's disease and type II diabetes. Angew. Chem. Int. Ed. 46, 1246-1252 (2007).

26 Bulic, B., Pickhardt, M., Khlistunova, I., Biernat, J., Mandelkow, E. M., Mandelkow, E. \& Waldmann, H. Rhodanine-Based Tau Aggregation Inhibitors in Cell Models of Tauopathy. Angew. Chem. Int. Ed. 46, 9215-9219 (2007).
27 Mishra, R., Bulic, B., Sellin, D., Jha, S., Waldmann, H. \& Winter, R. Small-Molecule Inhibitors of Islet Amyloid Polypeptide Fibril Formation. Angew. Chem. Int. Ed. 47, 4679-4682 (2008).

28 Nagai, A., Miyake, J., Kokado, K., Nagata, Y. \& Chujo, Y. Highly Luminescent BODIPYBased Organoboron Polymer Exhibiting Supramolecular Self-Assemble Structure. J. Am. Chem. Soc. 130, 15276-15278 (2008).

29 Nagai, A., Kokado, K., Miyake, J. \& Chujo, Y. Highly Luminescent Nanoparticles: Self-Assembly of Well-Defined Block Copolymers by Strong d-a Stacked BODIPY Dyes as only a Driving Force. Macromolecules 42, 5446-5452 (2009).

30 Goze, C., Ulrich, G. \& Ziessel, R. Unusual Fluorescent Monomeric and Dimeric Dialkynyl DipyrrometheneBorane Complexes. Org. Lett. 8, 4445-4448 (2006).

31 Bonardi, L., Ulrich, G. \& Ziessel, R. Tailoring the Properties of BoronDipyrromethene Dyes with Acetylenic Functions at the 2,6,8 and 4-B Substitution Positions. Org. Lett. 10, 2183-2186 (2008).

32 Zou, Z., Zhang, S., Cheng, Y., Liu, Y., Huang, H. \& Wang, C. Synthesis and enantioselectivities of soluble polymers incorporating optically active binaphthyl and binaphthol. J. Appl. Polym. Sci. 106, 821-827 (2007). 